\title{
PERCEIVING EXTERNAL THINGS AND THE TIME-LAG ARGUMENT
}

\section{Sean Enda Power}

Can we perceive things outside our mind or brain - what we might call external or distant things, objects and events? It seems that any theory we have about perception ought to say 'yes'. Otherwise, how can we say that we perceive the world in which we talk, think and live? A lot of important things in it are 'external' by this (very broad) meaning of the term."

But it might be asked: can we directly or immediately perceive external things; are they the possessors of the shapes, colours, weights, textures, sounds, and all other sensory qualities that are immediately presented to us in consciousness? It certainly seems that way. When I look out the window of the library to the distant mountains, I just seem to have a direct perception of the mountains. I do not seem to see them indirectly via seeing something else; seeing the mountains does not seem mediated.

This is not true of everything I might report seeing, e.g., watching a nature programme, I might report seeing a gecko mimicking a beetle - but it also seems to me that I am doing so via television images. Yet, one might think that this obviously does not apply to seeing distant mountains. Seeing the distant mountains is just like seeing the television picture. Both seem to be paradigmatic cases of seeing and of direct or immediate perception.

In addition, these mountains and television images certainly seem to be outside my mind and body. Indeed, much of what I directly perceive seems to be external like this. So, in cases where it seems this way, can it be the case that I do directly perceive external things? 
Let us call the perceptual thesis that what we directly or immediately perceive can be external things direct realism of external things - or, here, where we only consider apparent perceptions of external things, just 'direct realism'. Let us call the perceptual thesis that what we directly or immediately perceive cannot be external things, but must be something between us and the external things, indirect realism of external things - or, here, just 'indirect realism'.iii

The purpose of this paper is to consider one particular argument for indirect realism. This is the time-lag argument, which is: because there is a delay between the external things we seem to directly perceive and when we have the perception, then we only indirectly perceive external things. I suggest that this argument is compelling only if we subscribe to a particular, albeit intuitive, conception of time known as presentism. The argument loses its force if we hold another less intuitive conception of time known as eternalism. However, as eternalism is considered by many to be supported by contemporary physical theory whereas presentism is not, this counterintuitive position is also a common one amongst philosophers of time. And I argue that if we are eternalists, time-lags do not particularly threaten our direct perception of external things.

\section{Intermediate entities and Sense-data}

If the argument of this paper is sound, the time-lag argument does not particularly threaten direct realism. However, it is still only one argument used by indirect realists to deny that we directly perceive external things. There are other arguments, e.g., from (a) illusion or hallucination (e.g., Ayer 1982) and (b) the incompatibility of the properties we perceive with the properties of external things (e.g., shape, Moore 1953, colour, Hardin 1986; blur, Pace 2007). This leads to two important assumptions in this paper.

Given indirect realism, if we directly perceive anything at all, ${ }^{\text {iv }}$ then what we directly perceive will be 
some things between the external world and ourselves, i.e., they will be some kind of intermediary entity. General theories about the nature of such intermediary entities are not discussed here, e.g., whether they are non-physical entities, physical entities or non-physical properties of physical entities. This concerns the motivation for them from the time-lag argument. One particular indirect realism theory has been most commonly discussed in that argument. This is the sense-datum theory: very crudely, that intermediary entities are sense-data which bear the properties that are apparent to us in experience, e.g., colour, shape, timbre, etc. (e.g., Price 1950, Moore 1953, Ayer 1982).

To focus the discussion, an initially intuitive position will be assumed: that, whether or not we directly perceive internal or external things, we directly perceive something. Alternatively, if we wish to say that we directly perceive certain properties (e.g., phenomenal properties) then it is assumed that we directly perceive these properties because something bears them. It seems to me that taking this position as an indirect realist is to accept sense-data; as Moore introduce them, sense-data are only the bearers of the properties, e.g., the colours, shapes, weights, timbres, etc., that we directly perceive. ${ }^{v}$

Where appropriate, reference is sometimes made to intermediary entities and sometimes specifically to sense-data. The focus throughout is on whether or not we must only directly perceive these or if we can directly perceive external things.

\section{Transparency Theory and Disjunctivism}

This paper does not discuss the other arguments for indirect realism, i.e., (a) and (b) above. If these arguments are sound, then we cannot directly perceive external things, time-lag or not. Direct realists must still respond to such arguments. The target of this paper is not those convinced 
by such arguments. Instead, it is directed toward those who are not.

Some philosophers deny (a) and (b), e.g., transparency theorists and/or disjunctivists. But however successful they are against (a) and (b), their responses do not obviously apply to the time-lag argument.

Transparency theory is the position that what we seem to directly perceive is either identical to physical things or properties of physical things, and not something particular to experience itself; thus, experience is 'transparent', e.g., we seem to see the blueness of the sea rather than some non-physical 'blueness'. The examples of transparency theory tend to be entities external to us, although bodily things such as located pains also come into it (e.g., Tye 2007). Yet, as will be discussed, if the time-lag argument is sound, appearances are not relevant; however it might seem, we must directly perceive something internal; what we directly perceive cannot be something external like the blue sea.

Disjunctivism (at least some variations) deny that we directly perceive a 'common kind' of entity in perceptions and their perfect hallucinations/illusions. Thus, we do not need to directly perceive intermediary entities when perceiving (e.g., Hinton 1973; for discussion, see Haddock and McPherson 2008). Yet, the time-lag argument cannot be rejected by this method. The time-lag argument concerns only perceptions, not their perfect illusions or hallucinations. Trivially, there are common kinds of entities in perceptions and perceptions.

There is no intention here to assume any positions on the above debates. In particular, nothing is assumed about the relationship between what we directly perceive in perceptions and perfect hallucinations and illusions. However, due to the kind of perceptions discussed here, the range of what we seem to perceive is limited to the kind of perceptions to which transparency theories 
should assent. Here, we are concerned with apparent perceptions of external things, of entities at a spatial distance from our body and ourselves. We are not so concerned with cases where we also seem to perceive internal entities, such as, e.g., pains and thoughts.

The paper, then, is divided into three sections:

(i) The time-lag argument for indirect realism. Direct realist responses.

(ii) Motivations for accepting the argument even without considering the metaphysics of time. What these commit us to.

(iii) A denial of an important premise of the time-lag argument. This denial comes from an issue in the contemporary metaphysical debate about time.

\section{The Time-lag Argument}

Russell considers when we see the sun. We may seem to directly see the sun but we do not. '[W]here the sun seems to be now corresponds to the place where the physical sun was eight minutes ago.' (Russell 1948: 217). Thus, according to Russell, what one sees is something else (in his case, sense-data), through which we indirectly see the sun.

Implicit in Russell's claim is that, in order to directly perceive something, it must be simultaneous with the subject having the perception. ${ }^{\text {vi }}$ That the sun's location we seem to see is 'eight minutes ago' is sufficient to deny that we directly perceive the sun at that location. This seems intuitive: if I do see a leaf blow by the window, then the leaf is blowing by the window now. When I hear a bird singing, it is when the bird is singing. It is intuitive to think that what I directly perceive is when I seem to perceive it.

However, for this reason, the time-lag means we do not directly perceive what is external. The 
problem comes from how it is, according to established theory, that we get to perceive such external things. We perceive something external when a signal from it reaches us, and that takes time. It follows, then, that there is an interval between when an event occurs and when we perceive it - the time the signal takes to travel from the event. But this means that what we believe we perceive is not happening right now, but actually happening some time in the past.

This lag applies to processes underlying all sensory perceptions of external things but the striking examples are from processes underlying sight. I see the leaf because it reflects light onto my retina, leading to a process which results in my perception of the leaf. Since $17^{\text {th }}$ century measurements by Römer, it has been known that light has a finite speed (e.g., Römer in Shapley and Howarth 1929; Moritz 1970; Zajonc 1993). As such, it takes time for light to reach me from its source. But its source is what I seem to see. Thus, what I see of the leaf, the sun, etc., is in the past. Something similar can be of course be said about hearing traffic; the source of the sound is in the past, even though that is what I seem to hear.

Thus, the argument goes, we seem to perceive what are actually past events and not events simultaneous with our perceptions. Yet, only perception simultaneous with perceived events is direct perception of those events. Therefore, we do not directly perceive what we seem to perceive; we must indirectly perceive it (perhaps, through it, e.g., causing our perception).

Yet, why must direct perception be simultaneous with the perceived events? Ebersole and Ayer both argue as follows: we think that we have direct perceptions of external things, e.g., a football kick or a concrete object like a distant star. However, it takes time for signals to reach us from those events: in the case of the football kick, a mere millisecond; in the case of a star, perhaps thousands of years. By the time the light reaches us, the thing we seem to perceive may have ceased to exist, e.g., in the intervening years, the star has exploded or faded in its luminescence. 
Thus, what we seem to perceive is not something that is occurring or exists. 'It is possible [...] that there are no stars, no such physical things. Our visual data do not imply stars exist. Physical stars must be one thing, our visual data quite another.' (Ebersole 1967: 509). And it is also possible that, even if the star still exists, it no longer glows as it does, e.g., it is not so bright. Our visual data do not imply the brightness. That bright glow must be one thing, our visual data another. Yet, (it is assumed here) we do perceive something, irrespective of whether or not the star exists or glows like that. Therefore, what we perceive must be different to the star itself, e.g., sense-data.

Thus, there is a negative and a positive claim in the time-lag argument. The negative conclusion is that, since our perception of external things is not simultaneous with the external things themselves, we do not directly perceive the external things. The positive conclusion is that, since we perceive some things directly, and thus simultaneously with our perceiving, it must be some things other than the external things we believe we perceive. These 'some things' are the intermediary entities of indirect realism, e.g., sense-data.

\subsection{Response: Directly Perceiving the Past}

The most direct counter-attack against the time-lag argument is this: the subject having the perception does not have to be simultaneous with the external thing directly perceived. As Ayer puts it, the time-lag argument 'draws its strength from the fact that one tends to think of seeing as concerned only with the present [...] whatever it is that we see must exist here and now if it exists at all. But this assumption is not unassailable. Why should it not be admitted that our eyes can range into the past, if all that is meant by this is that the time at which we see things may be later than the time when they are in the states in which we see them? And having admitted this, why then should we not also admit it is possible to see things which no longer exist?' (Ayer 1982: 94-95). 
The time-lag argument lacks something belonging to a similar argument from hallucination. Unlike hallucinations, what we perceive actually existed. Le Morvan writes:

The claim "if something no longer exists, we cannot now perceive it" can be interpreted in at least two distinct ways: (a) if something no longer exists, we cannot now perceive it as it presently is, or (b) if something no longer exists, we cannot now perceive it as it used to be. When taken in the sense of (a), the claim is obviously true, or so we may suppose. But when taken in the sense of (b), the claim is far from obviously true. For why couldn't we now visually aware of something as it was which no longer exists? ...

(Le Morvan 2004: 223-224)

However, this response has problems as well. 'We not only see the distant past but we often point to it; we point to the distant past, it being right now before us.' (Ebersole, op. cit: : 516). How can we point at past things before us? Surely these so-called 'past things' are present things? Similarly, Dretske states that such a response is a resort to 'heroic methods' and an 'outright sacrifice of common sense in order to save common sense.' (Dretske 1969: 72). The point being: it is counterintuitive to hold that we directly perceive the past.

Yet, this is not the end of the discussion. According to Ayer, directly perceiving the past is only counter to pre-theoretical intuitions, ones we have before we encounter physical laws. Given the time-lag, the star we seem to see shining in the sky is shining in the past. If we accept this we have to give up at least some pre-theoretical intuitions: either that we directly perceive only what is happening now or we directly perceive external things. '[W]e have to balance the oddity of saying that we can see what is past against the oddity of saying that we do not see physical objects; and to give our eyes access to the past may well seem the more reasonable course.' (op. cit.: 94-95). 
The issue is not whether our direct perception of the past is pre-theoretically natural to us, i.e., it is not about the common-sense or naïve view, but how it compares to the thesis of indirect realism. Directly perceiving the past may sacrifice common-sense but common-sense must be sacrificed in any case.

Finally on this response, Ebersole raises a question about the intuitive force of the simultaneity of what we perceive and having a perception: "'we do not see the present of the stars but only their distant pasts". Does this counter an error, a "common-sense" mistake, one that all of us make? I do not know what it could be. Chisolm seems confident that it does: "... we tend to assume, until we are taught otherwise, that any event or state of affairs we perceive must exist or occur simultaneously with our perception of it." How did he find this out? Do we all assume this? Could we ask and learn?' (Ibid.: 519; see Hinton 1966 for comment).

I disagree with Ebersole here, and agree with Dretske and Chisholm. Insofar as there is a common-sense view on these matters, it is that we directly perceive only what is happening now. The question is: why do we have this view? Perhaps it is because of two intuitive assumptions.

(i) The things that we directly perceive are real; It is assumed here that this is uncontroversial.

(ii) What is not happening right at this moment, but instead is only past (or future) is not real. However, unlike (i), (ii) is controversial. One significant strand in the contemporary metaphysical debate about time questions this intuitive assumption; in particular, as we will see, it seems we must deny it due to issues regarding contemporary physics. 


\subsection{Directly Perceiving The Spatial Arrangement of Things}

There is a further issue here, concerning the spatial arrangements of what we perceive. If we directly perceive external things as we seem to do, then we ought to also perceive the spatial relations between them. Now, it is uncontroversial that we can be mistaken about particular spatial properties; we commonly misinterpret the relative distances (and indeed sizes) between things, e.g., the stars we seem to see may appear to be twinkling just above the trees. However, it is much more compelling that a great deal of what we directly perceive is external; perhaps the stars are not that near but that they are outside of our own bodies seems uncontroversial. If this is so, then what we directly perceive is at a spatial distance from us, i.e., it is spatially related to us (although we may not know the exact spatial relation).

However, according to Houts 1980, even if we do directly perceive past external things, they cannot be spatially related to us: '[no] presently existent physical thing is at any spatial distance from any presently non-existent physical thing. For example, I (or my body) am not now at any spatial distance from the atomic blast over Hiroshima.' (Houts 1980: 151). Thus, the past things I directly perceive are at no spatial distance from me. True, if they still exist now, the things that I perceive may be at some physical distance from me now. But the question is: 'at the time of perception, are we (or our bodies) always, or ever, at some spatial distance from the physical events and stages that we perceive?' (Ibid: 152). Not if what we perceive are past things, so Houts' claims.

This undermines the appearance of external things; even if what we directly perceive was external, it is not external now; what we might call something's 'being external' is a spatial relation between it and ourselves; it is external by not being here, by being at some distance from us. Yet, if it cannot be spatially related to us, then it clearly cannot be at a distance to us; thus, it cannot be external, 
denying how it appears.

Worse yet, not only are things that seem to be some spatial distance from us not distant from us, but many of them are not even spatially related to each other. Imagine you stand in the centre of a circle of stars, the light from each of which reaches you now. The light from each star you perceive is emitted at the same time; thus, each thing you perceive is spatially related to the other things you perceive, each thing being at the same time. Now, Houts asks us to imagine that we look out on a clear night and see the stars, the moon and our own hand (ibid: 155). As far as we can tell, these appear to stand in spatial relations to each other.

However, each of these things is a different distance from us. The light from each of them takes a different amount of time to get to us. Thus, my perceptions are of each as it is at a different time: my perception of my hand is of my hand as it is a later time than what I perceive of the moon, and my perception of the moon is as the moon is at a time later than what I perceive of the star. If Houts is right, things at different times are not spatially related; thus, my hand, the moon, and the star as I perceive them are not spatially related. They appear to be spatially related but now appearances and reality do not line up. '[D]o we ever observe physical events and stages which are or were in a three-dimensional array? The answer, as I have argued, is, No. At best, our field of view appears to have depth, appears to be an array of events and stages ordered in three dimensions.' (ibid: 156).

Unsurprisingly, this is an important consequence for direct realists who support direct perception of the past: it undermines any direct perception of three-dimensional space. Even if we directly perceive past things, we do not directly perceive their three-dimensional spatial relations. Yet we seem to perceive these spatial relations as directly as we perceive the things themselves. 
Indeed, the relation between spatial relations and objects is much more intimate; given the things have shape, as they do if they are physical objects, we arguably need to perceive their spatial relations to perceive the things themselves. In particular, for external things, we see the threedimensional spatial relations of their shapes. If we do not directly perceive three-dimensional relations, then we do not see the shape of external things themselves. How then can we even say we see external things, given they are three-dimensional?

But should we make this assumption with Houts? Again, this assumption depends on one's metaphysical conception of time. Given a different position, it is not so obvious we must say this; indeed, doing so raises particular problems for indirect realism, as will be seen.

\section{Perceiving Simultaneity and Space}

It might be that the time-lag argument is independent of ones' concept of time. This section examines that possibility. As discussed, the time-lag provides two motivations for indirect realism:

(a) We only directly perceive what is simultaneous with our having the perception, and thus not external things. In response, some argue that we can directly perceive what is not simultaneous with our having the perception.

(b) We may directly perceive past things, but past things are not spatially related to us (or, in many cases, to each other); thus, what we directly perceive are not external to us, contra to how they seem.

Given the response to (a), there seems to be a simple rejoinder to (b): past things can be spatially related to us (and each other). This has not obviously been advanced in the literature. But for 
reasons related to simultaneity, there is argument against this given one's conception of time.

The deeper issue concerns (a): Is it necessary for (i) what one directly perceives to be simultaneous with (ii) one's perceiving or having the perception? The difference between these is discussed below, in order to explore two issues: first, in light of such discussions, if there are any problems in particular from the time-lag for direct realism; second, if indirect realism is any better for avoiding such problems. This leads us then to the next section, on the metaphysical conceptions of time.

\subsection{The Spatial Relations of What We Directly Perceive}

Regarding appearances of external things, which has the advantage? If we do directly perceive external things, then the external things that we directly perceive can be spatially arranged as they seem to be arranged. This is the case if they can be spatially related over time, contra Houts. But even where they are not, if they still exist, the star, moon and my hand may be spatially related as they seem to be. However, this does not work as well for intermediate entities such as sense-data.

Can intermediate entities stand in these apparent spatial relations? Perhaps, but only if we concede further counter-intuitive views than those already present in such theories. If they do not, then they cannot be arranged as they appear to be arranged. Thus, appearances do not given the advantage to indirect realism over direct realism.

Say we directly perceive intermediary entities now, i.e., all at one time, and they are spatially related, and they are where they appear to be. Then, since they appear to be external, the intermediary entities will be at a distance from us in external space, i.e., the intermediary entities will occupy external space. If so, two statements must be true of these entities: 
(i) Although intermediaries between far away, past things and ourselves, the mediating entities are also where those far away things are.

(ii) The intermediate entities in a single perception of variously different things are all happening now. Thus, each entity occupies its distant, external location at the same time as all the others.

Thus, external events that we seem to perceive are (somehow) succeeded by mediating entities entities which then occupy the same location as the external events. Yet, each mediating entity does so after significantly different durations, e.g., my hand's mediating entity does so after hundreds of millionths of a second, the moon's after a few seconds, the star's after a few years. These are different durations which somehow ensure that we perceive these entities simultaneously. How could there be such entities out there at those places, perceivable only when stimuli from other events at their location reach us? Do we put them out there? - Literally project what we directly perceive out into external space, instantaneously moving them to the locations of

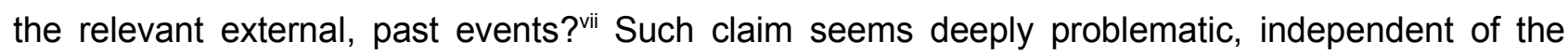
debate here (see Moritz 1970 for a closely related discussion).

A more plausible thesis is one of the following: if intermediate entities have any physical spatial location at all, then they are a local effect of distant events, e.g., in the brain (e.g., Smart 1970). Alternatively, perhaps, they have no spatial location (if one is a dualist, and believes further that what we directly perceive are mental entities, one might hold this latter view). An anonymous referee has raised another interesting possibility: most sense-datum theorists from Price on accept that sense-data have a property of private phenomenal depth. We might take this as a special case of sense-data being spatially arranged in a private phenomenal space. So, perhaps sensedata (or other intermediary entities) are spatially arranged as they seem to be, given that they are 
arranged in this private phenomenal space.

However, in all of these options, given we seem to perceive things that are external, no such intermediary entities will be spatially arranged as they seem to be arranged. Again, we seem to directly perceive things spread out over an external space, e.g., we seem to see the moon and stars at a remove from our own body. An external space is a public space; it is not private in any sense desired here (my garden is private in some sense, but it is public in that it can be moved through by something like a cat). Intermediary entities may be in the brain, nowhere in space, or in some private space; but if they seem to be out in external space, they are not in the space they seem to be in.

Thus, Houts' argument is not obviously an argument from appearances to indirect realism - unless, that is, the intermediate entities occupy external space. We may directly perceive the actual spatial relations of, e.g., sense-data, private or otherwise, but these spatial relations are not the spatial relations that they seem to be. Of course, if Houts is right otherwise, and external things cannot be spatially related at all, indirect realism does have this advantage: what we directly perceive can be in some spatial relations, unlike the external things of direct realism.

\subsection{The Simultaneity of Perceiving and What We Perceive}

There is still the main time-lag argument: we perceive mediating entities rather than external events because we perceive something now, i.e., our perceiving is simultaneous with what we perceive.

Given the discussion of the last section, appearances do support this; indeed, this is just why the time-lag is so surprising. We look at what seems to be a distant star and it appears to be shining 
now. So, how can a direct realist seriously claim that we are seeing it shine many years ago?

One response might be draw an analogy with our failure to perceive distances: we do directly perceive past things, e.g., distantly shining stars; however, just as we can be mistaken about the distance between ourselves and these stars, we can be mistaken about when they are shining as well. For example, if I look down a row of houses on a street, then I look at events at a variety of earlier times. From where I stand, I see each house illuminated at an earlier time than any houses nearer than it. The whole row recedes into both the distance and the past. It is just that neither 'how far' nor 'how long ago' of what I see is easily apparent to me; I must work them out.

Is this plausible? It certainly does not seem to be common-sense, as has already been discussed. But what other reason is there to prefer the simultaneity of what we perceive with our having of the perception?

One consideration is this: the external things which we seem to directly perceive seem simultaneous with other things which are happening now. These include what I do and what happens to me, e.g., my thoughts, my own actions, myself indeed at this particular place from which I view the star. It seems correct to say that these are happening at the same time as I am having the perception. For convenience in this paper, this is assumed (although relativity, which is relevant later, does affect this assumption). If direct realism of external things is true, and there is a time-lag, then why does the shining star seem simultaneous with my thoughts about it, or indeed other local events, such as events in my body, including whatever happens to me - including having the perception?

One response comes from Power: we do not perceive simultaneity between $x$ and $y$; rather, we fail to perceive duration between $x$ and $y$. In this case, the distant star and my own thoughts, actions, 
etc. seem to be simultaneous only because I fail to perceive the durations between them (Power 2010).

This may be a response to the simultaneity between the various things that we directly perceive. Yet, there is a separate issue that seems at least as important and problematic. This concerns the simultaneity of what we directly perceive with our perceiving them. A certain way of thinking about the relationship between these undermines any direct realist response. However, I will suggest that this response is not particular to the time-lag argument. It is a general issue for direct realists of external things.

The positing of intermediate entities must succeed because there is no time between their existence or occurrence and the subject having the perception. If there is such a delay, no matter how brief, the intermediate entities are themselves indirectly perceived; the time-lag argument applies to our perception of intermediate entities, making it redundant as an argument for indirect realism.

How might intermediate entities be simultaneous with our perceiving them? One answer is this: intermediate entities occupy the same place as having the perception of them. There is no delay because there is no space which signals must cross. However, this raises another question: are the intermediate entities different to the perceptions of them; that is, are they numerically distinct from perception? If they are, then more than one thing occupies the same space; what we directly perceive and the perception itself spatially coincide.

Can we assume this coincidence? Given one understanding of the relationship between perception and what we perceive, it seems unproblematic: if perceiving happens anywhere, it happens where what we perceive happens. However, there is a problem once we consider what we include here in 
both a perception and what we seem to perceive.

\subsubsection{Perceptual Structure}

Throughout this paper, reference has been made to a subject's 'perceiving' or 'having a perception' as distinct from what a subject (directly) perceives. I take this distinction from Moore, who drew something close to it between sensing, having a sensation and what we sense (sense-data; Moore 1953). Here, three closely related questions are asked:

(i) What is perceiving or having a perception, and how is it distinct from what we perceive?

(ii) When does the perceiving or having a perception happen?

(iii) How should when the perception happens relate to when what we directly perceive happens?

If there is no distinction between having a perception and what is perceived, the answers to the last questions are trivial. As they are the same, the relation is identity, i.e., 'they' happen at one time, simultaneously, because 'they' are an 'it'. Yet, along with Moore, I do not think we should hold this identity (see below).

Let us go into a little more detail about the structure of perception. I assume in this discussion that there are three important elements, parts or constituents of the perceptions considered here. These are:

(a) Subjective activity: when a subject has a perception, something happens to the subject. (This is a very minimal understanding of 'subjective'). What happens may be mental or physical (if there is a difference), e.g., thoughts, neural events. There may be nothing apparent in this activity. All that matters is that it is whatever happens to the subject of the perception when they have the perception. It obviously includes their perceiving or having the perception, but it can also include 
other things (see below).

(b) Relational (or intentional): a direct perception is a relation between ourselves and something; we directly perceive something; some think of this relational feature of perceptions as its intentionality (following Brentano; see Jacquette 2005 for discussion); others may disagree. Here, it is assumed.

(c) Phenomenology: we seem to perceive external things. This may not be necessary for perception generally (e.g., Humphrey 2008). However, it is here, as I am concerned with cases where we seem to perceive external things.

Phenomenology gives rise to two further important features of perception.

(ci) Spatial appearance: When having a perception of what seems to be external things, the subject appears, to themselves, to be spatially separated from much of what they directly perceive. This is just why what they directly perceive seem to be external.

As such, what we seem to perceive happening out there is accompanied by something else: a sense of ourselves, as subjects having the perception, located in space. One might call this an awareness by the subject that they have a spatial point-of-view or even, perhaps, that they are embodied. I consider this distinctness necessary for something to seem external or distant; what we perceive has to seem external or distant to something else, e.g., in the case of embodied beings such as humans, apparently external things seem to be outside human bodies. viii

(ii) Internal phenomenology: having a perception does not just involve what seem to be external things, and our own distinctness from them; we also seem to be aware of internal things. Besides 
what seems to be my body located here and the distant mountains there, I seem to be aware of my thoughts and my pains.

This is important; this paper assumes (for simplicity) that this internal activity is simultaneous with the subjective activity of a perception, e.g., we seem to have our conscious thoughts about what we perceive when neural activity related to what we perceive is happening. It is also intuitive to suppose that when internal phenomenology and subjective activity happens is when one is perceiving or has a perception. Analogously, the place where such activity happens, and perhaps the accompanying thoughts, may be thought of as the place where one has a perception. ${ }^{\text {ix }}$

These elements of perception allow examination of issues concerning the relationship between when we are perceiving or having a perception, and when what we perceive occurs.

\subsubsection{Having a Perception.}

Some philosophers understand the distinction between perceiving or having a perception, on the one hand, and what we perceive, on the other, as a difference between act and the object of the act. Perceiving or having the perception is the act; what we perceive is the object of that act. If so, and we understand action as something that happens to us, then direct realists have a problem. However, this is a problem that goes beyond the time-lag argument, at least regarding distant things.

Let a broad interpretation of 'action' be assumed here: action is something that happens to us. What is of most interest here is what happens to us when we are perceiving, i.e., subjective activity. So, 'action' here is the subjective activity. (One might, of course, specify a narrower meaning: action is something we do, and what we directly perceive is a result of that action. 
However, other than some very special cases, e.g., we directly perceive the spaghetti we're boiling, this eliminates direct perception of external things; moons and mountains are not the results of what we do).

As stated, such subjective activity is necessary for perceiving. But how is it related to what subjects directly perceive? One suggestion comes from an anonymous referee: what we directly perceive is a constituent of what happens to us. What we directly perceive is, we might say, part of what we happens to us.

If so, the time-lag argument is sound, despite any further issues concerning our conceptions of time.

\subsubsection{Perceptual Content as Part of What Happens to Us.}

The anonymous referee's challenge to direct realism is worth quoting in full:

'[l]t seems to me to be very plausible to say that an act or event and its content must temporally coincide/overlap. For example, to say that World War II happened between 1939 and 1945, but that (some of) the battles that made it up took place before 1900 would make no sense. On any account of time, the act/event of my perceiving the star now takes place now. If the act is (partly at least) essentially composed of its content, and the content is (some feature of) the star I see, that feature must exist when the event/act of my seeing exists. It might be argued that I can be part of a process that starts before my existence (and goes on after it) - e.g. 'human history' - but this does not show that something can happen to me or that I can do something at a time when I do not exist.'

The assumption here is that what I directly perceive (the 'content') is part of what happens to me. 
What happens to me, including what I directly perceive, cannot happen when I do not exist; hence, the time-lag argument succeeds.

Yet, should a direct realist about external things share this assumption even if there were no timelag? To do so requires assent to one of the following distinct alternatives:

(i) What I directly perceive is something that happens to me and is where I am.

(ii) What I directly perceive is something that happens to me and is somewhere else than where I am.

A direct realist must deny (i). If it is (i), then what I directly perceive cannot, by definition, be something external; external things are not where I am. There is no need for a time-lag; all that is required for denying direct perception of external things, i.e., things there, is that we only directly perceive what happens here.

A direct realist might admit (ii), as it allows us to directly perceive things elsewhere. Thus, (somehow or other) what happens to a subject is something that happens at a distance from them. What happens to us need not happen where we are.

Yet (ii) raises this question: why is it we can say of space what we cannot say of time? Why is it that what happens to us can be where we are not if what happens to us cannot be when we are not?

This option points to a different response for the direct realist. If a direct realist wants to hold that we directly perceive external things (or their properties), they should resist a more basic claim in this analysis of perception; they should argue against the claim that what we directly perceive, when we perceive external things, is always something that happens to the subject. Given direct 
realism, some external things (and their properties) are independent of the subject that directly perceives them. What happens to the subject is not independent of the subject. There may be many challenges to the direct realist doing this, (e.g., perhaps the same challenges as those for transparency theory), but they are not particular to the time-lag argument.

So what is it that is particular about our relation to things at other times which is not there in our relation to things at other places? Again, a response could be that the claim that what I see is when I exist is more compelling than the claim that what I see is where I exist. We should not presume an analogy here. One may happily admit that what we directly perceive is else-where but less happily that it is else-when.

This may be so. Yet, again, if this unhappiness is due to common-sense or appearances, it is common-sense and appearances which are undermined whichever side we take. The question here is not whether we should abandon common sense or appearances, it is how they should be abandoned. Should we follow the intuitions of indirect realists or direct realists?

Let us consider what the metaphysics of time does for this question.

\section{The Metaphysics of Time}

The time-lag argument is based on a physical assumption: signals from events take time to travel across space. This includes light: light has a finite speed, and so any distance between something and seeing it makes it earlier than what happens to the subject when they see.

However, light does not only have a finite speed; according to modern physics, light has an absolute speed. This is fundamental to relativity theory. If having a perception and what we directly 
perceive are at different points in space, relativity undermines the following claims in support of indirect realism:

(a) Directly perceived $x$ is simultaneous with having the perception.

(b) Only what is what is simultaneous with $x$ is spatially related to $x$.

\subsection{Contemporary Physics and the Time-Lag Argument}

According to the conception of time in relativity theory, simultaneity is relative between spatially separated events or things. This relativity is to arbitrary and conventional inertial reference frames, i.e., frames defined by velocities. Two spatially separated events which are simultaneous according to something moving at one velocity may be at different times for something moving at another velocity, e.g., according to a station guard, beams of light may simultaneously reflect off two mirrors in a station, yet reflect at different times according to a passenger on a moving train (see, e.g., Sider 2003; Power 2010).

Assume for now that the intermediary entities are separated in physical space from everything else that happens when we perceive them, e.g., other subjective activity. If it is frame-relative that two events separated in space are simultaneous or at different times, it is frame-relative whether such entities are simultaneous with or at different times to the other subjective activity. Yet, such activity happens when we are perceiving, and the motive of the time-lag argument for indirect realism depends on perceiving being simultaneous with what is directly perceived. If the simultaneity of our

perceiving and intermediate entities depends on some reference frames, direct perception of intermediate entities is only relative to some reference frames. From other frames, by the definition here, we have indirect perception of them. 
This temporal relativity need not hold between all events standing in spatial relations. Causes that are at different times to their effect are so in all frames, irrespective of how they are spatially located. However, clearly, advancing this kind of relation between having a perception and what's directly perceived denies outright that having a perception and what's directly perceived are simultaneous; to be relata here, they must be at different times.

A better alternative is the other case where two things can be absolutely simultaneous: entities may be simultaneous in all frames given they occupy the exact same spatial location. Thus, perceiving and what is directly perceived spatially coincide. In that case, they may be simultaneous.

However, there are problems with articulating the spatial coincidence of what we directly perceive and having a perception.

\subsection{The Spatial Coincidence of What We Directly Perceive and Perceiving}

Consider the elements of perception listed above: what we perceive; subjective activity (what happens to us); what seems to be our own position in space; internal phenomenology. Given the reply here, all of these are spatially coincident.

This response raise problems regarding these elements' correlations with the physical world (originally raised in Power, op. cit.). The problems extend beyond the scope of this paper. However, a brief discussion may suffice to show the issues.

If these elements are physically spatially coincident, then there are two possibilities for such correlation: 
(ai) All of these elements share the same physical correlate which occupies that space.

(aii) There is a different physical correlate for each of them, but all of these physical things occupy the exact same region of space.

Consider an example: I have a headache as I think of the colour of my hand, which I see (indirectly or directly) standing starkly against a blue sky. Given the issue above, each of these elements either require a separate physical correlate or else they are correlated with the same physical thing.

However, if (ai) several different correlates are in the same place, then there are multiple physical entities in one place. This is physically unjustified: each of these is only defined at this stage by being a correlate of a different element of the perception; there is nothing yet physical defining their differences. Nor does there seem to be any evidence for such a multitude of physically overlapping correlates. In sum: what makes these distinct correlates physical and what reason do we otherwise have to believe in them?

Yet, (aii), that there is a single physical correlate for all elements, is also problematic. There are no multiple physical entities but there still needs to be an explanation for how this single physical thing, the physical event or object, can be correlated with significantly distinct elements of the perception. Say neural assembly $B$ correlates with all the elements in the example above. How do we explain its correlation with my thought about my hand? How do we explain its correlation with what appears to be my hand? And the ache? And what seems to be the background sky? The problem is that whatever explanation we give for one such correlation, it cannot be the same as another; how $B$ relates to a thought about hands is not the same 'how' as how $B$ ' relates to my seeming to see the blue sky. ${ }^{x}$ 
For such reasons, it is problematic to assume that there is physical coincidence between (i) what we directly perceive and (ii) what happens to us when we are perceiving or having the perception, e.g., our thoughts about what we perceive, our own body's aches and pains, etc. The better alternative is to hold that the intermediate entities, e.g., the sense-data, have spatially distinct physical correlates from what happens to us when we are perceiving. But this makes what we directly perceive and the rest of the perception either only simultaneous in some frames or not at all (if causal).

Thus, the theory of relativity raises particular difficulties for the assumption that what we directly perceive is simultaneous with everything else that happens when we have a perception.

Relative simultaneity also has similar consequences for Houts' claim that there are no spatial relations between things at different times. In that case, only simultaneous things can be spatially related. Yet, again: if events are simultaneous and spatially separated only relative to some frame(s), and are at different times in some other frame(s), then events in the latter frame are either

(bi) Not spatially related at all, because they are at different times.

(bii) Spatially related and at different times.

If (bi) is true, what we directly perceive are spatially related only in some frames. In others, they are not. Thus, by taking on Houts' assumption, we make spatial relatedness frame-relative, dependent on a velocity. Yet, if (bii) is true, the assumption is denied: things at different times are spatially related. ${ }^{\mathrm{x}}$ 
It seems that, in order to preserve the assumption that things at different times are not spatially related, and remain consistent with relativity, one must hold that one's frame, i.e., one's velocity, determines whether or not such events are actually spatially related. I consider this far more counter-intuitive than the alternative. Still, as intuitions are problematic in any case, I leave the discussion here. What is hopefully shown here is that a direct realist response to the lag is not the so obviously worse than the indirect realist response.

Might the problem here be relativistic physics? Perhaps this shows we must reject relative time for perception. There are two ways this can be done.

First, we (i) constrain relative time only to physical events, (ii) insist that perceptions not be conceived as physical events, and, thus, (iii) argue that relative time does not apply to perceptions. However, there are problems with such an approach. As with the coincidence response, these go beyond the scope of this paper (requiring, undoubtedly, further work) but a brief discussion of one problem may suffice.

If we limit relativistic time to physical events, we must limit its temporal relations to physical events, having other temporal relations for mental events. Thus, there must be separate physical temporal relations to mental temporal relations. But then there is a problem with mind-body interaction. Causation requires temporal relations between cause and effect; cause precedes effect. If one denies that there are temporal relations between physical and mental things, then how can there be this causation between them? How can a mental cause precede a physical effect, or vice versa, if they do not share temporal relations?

Those who insist on this view at the very least owe an account of non-temporal causation, or some alternative to causation itself, in ways that explain how what seem to be temporally related physical 
and mental events are not so related. (For discussions related to this, see, e.g., Lockwood 1984a and 1984b, Gibbins 1985, Weintraub 1998, Smythies 2003, Allen 2006).

Second, deny the standard interpretation of relativity outlined above. Space and time are not relative to some arbitrary and inertial references frames. They are absolute. Notably, this is the approach of those who insist on a particular metaphysical position in the debate about existence in time. So, to close this paper, we turn to how the time-lag argument relates to the positions in that debate.

\subsection{The Metaphysical Debate about Temporal Existence: Presentism and Eternalism}

As noted at the end of section 1.2., there is an issue with claiming that we perceive things that are only in the past. What is only in the past no longer exists; how, then, can we perceive it? This problem is not reflected in what might be considered the analogous spatial case of perceiving distant things.

I assume that the statement that 'what is only in the past no longer exists' is trivially true: if it is only past, it is not present; if something 'no longer exists', it does not exist now; and I take it that, if $\mathrm{x}$ is 'not present', then $x$ does not exist now. So, if $\mathrm{x}$ is only in the past, then $\mathrm{x}$ no longer exists.

However, that what is only in the past does not exist, where 'exists' is unqualified (by 'no longer', at least) is a different issue. It is an issue which takes us into a current metaphysical debate about time. This debate concerns two different conceptions of what exists or is real in time.

According to the position of presentism, only what is present exists. Nothing at other times than the present exists (e.g., Hinchliff 1996, Prior 1998). Even what happened only a second ago does not 
exist; neither does what will happen in a millisecond after you read this. In contrast, there is eternalism: what exists at any time is equally as real as what exists at any other time, irrespective of which time is present (e.g., Le Poidevin 2003).

Presentism is typically claimed to be the default position on time. Indeed, according to some presentists, to think otherwise is to misunderstand the concept of time (e.g., Geach 1998, Prior 1998). Eternalists have not agreed, arguing that presentism leads to more problems than it solves (e.g., Le Poidevin, 2004). Notably, they argue that presentism is incompatible with relativity theory (e.g., Sider, op.cit.). In response, presentists have insisted that our pre-relativistic or commonsense conceptions of time are too fundamental to be revised by physical considerations (e.g., Prior 1998, Geach 1998; see Sider 2003 for rejoinders).

What is the affect of holding presentism on our perception of external things and events? Given that there is time-lag, presentists must be indirect realists. They are committed to what an eternalist is not: at the time the perception occurs, the thing perceived no longer exists, and for a presentist, this means that there is no such thing. For a presentist, then, arguments which favour direct realism lose a lot of their force: even if the star I see shining in the sky exists in some unqualified sense, because it still exists, the actual shining I perceive does not.

Similarly, Houts' assumption that things at different times are not related spatially is correct; given one thing is present, the things at other times are not present; thus they do not exist. Lacking existence, they do not have spatial relations with anything (even if they once did). Thus, if I seem to perceive them in any spatial relations, this perception would be illusory. But Houts' point is rather insignificant in comparison to what makes this so: that, for a presentist, if I seem to perceive such things in any way at all, this perception is illusory: being past, they do not exist. 
Thus, it seems that, for the presentist, the time-lag argument for indirect realism works. Why is this? Perhaps presentism turns the time-lag argument into something like an argument from hallucination. For a presentist, past events are as open to our direct perception as the apparent objects and events in hallucinations; a star shining in the past can no more be directly perceived than the pink rats in a fever-driven dream.

Given eternalism, however, we are not committed to the idea that the external events and things we seem to perceive do not exist. Although they may no longer exist, this does not deny their unqualified existence. As such, eternalists might hold that we can directly perceive external things. What must be said about them, however, is that they are not happening at the same time as we are having the perception.

Some eternalists might still hold that indirect realism is true, e.g., because of arguments from hallucinations and illusions. However, should they do so because there is a time-lag? We have examined some intuition-driven motivations to do so. However, we have also discussed a problem from relativistic physics. And this brings us to one significant motivation for holding eternalism over presentism: relativity itself. If one is an eternalist, one is very likely to accept relativity. If so, then this paper argues that they should reject the time-lag argument's basic assumption: that what we directly perceive must be simultaneous with the subjective activity of perceiving.

\section{Conclusion}

We have discussed the following:

(1) The time-lag argument against direct perception of external things.

(2) The direct realist response to the time-lag: that we directly perceive things at other times.

Problems with this response. Whether or not such problems are particular to the time-lag or 
problems for direct realism generally.

(3) An issue for the indirect realist assumption of simultaneity between perceiving and what we perceive from relativistic physics. Possible indirect realist responses, and their problems.

(4) Two metaphysical conceptions of time, and which sides advocates of these conceptions can take in this debate. Presentists must be indirect realists; eternalists could be direct realists.

As discussed at the start, it may be that direct realism and presentism are both false positions. There are other arguments than the time-lag argument for indirect realism. In addition, this paper has concentrated on what we seem to see, e.g., on seeing our hand, the moon, and distant stars, and directly perceiving these external things seems intuitive. However, it may be more problematic to claim that we directly perceive external things given other kinds of sensory perception. When I step out into my garden and look at the night sky, I can smell the jasmine by the gate. There is a time-lag between pollen leaving the surface of the flower and my smelling it. But do I directly perceive here the analogue of seeing the star? That is, do I smell the pollen as it leaves the flower?

Perhaps some perceptions of external things are more direct than others; perhaps our intuitions about this are not dependable. There is further work in this. Here, the hope is only to show that the time-lag does not deny the possibility of directly perceiving what we appear to perceive, that is, external things.

\section{Acknowledgements}

Many thanks to Robin Le Poidevin for extensive and detailed comments on earlier drafts of this paper; these drafts have also benefited from further comments by an anonymous referee of the original submission and many conversations with Maria Kon. 


\section{References}

Allen, S. (2006), 'A Space Oddity: Colin McGinn on Consciousness and Space', Journal of Consciousness Studies, 13: 61-82.

Austin, J. L. (1964), Sense and Sensibilia. London: Oxford.

Ayer, A.J. (1982), The Problem of Knowledge. Harmonsworth: Pelican.

Casullo, A. (1987), 'A Defense of Sense Data', Philosophy and Phenomenological Research, 48: 45-61.

Clark, R. (1987), 'Objects of Consciousness: the Non-Relational Theory of Sensing', Philosophical Perspectives, 1: 481-500.

Dretske, F. (1969), 'Non-epistemic seeing', in Seeing and Knowing. London: Routledge.

Ebersole, F. (1965), 'How Philosophers See Stars', Mind, 296: 509-529.

Geach, P.T. (1998), 'Some Problems with Time', in Van Inwagen, P. and Zimmerman, D . (eds.) Metaphysics: The Big Questions. London: Routledge.

Gibbins, P. F. (1985), 'Are mental events in space-time?', Analysis, 45: 145-147.

Haddock, A, \& McPherson, F. (2008), Disjunctivism - Perception, Action, Knowledge. Oxford Scholarship Online: Oxford University Press. Accessed 16 September 2009; URL=<http://0dx.doi.org.wam.leeds.ac.uk/10.1093/acprof:oso/9780199231546.001.000>. Hardin, C.L. (1986), 'The Ontology of Color', in Color for Philosophers. Cambridge, Hackett. Hinchliff, M. (1996), 'The Puzzle of Change', Nous, 30, supplement: Philosophical Perspectives, 10: 119-136.

Hinton, J.H. (1966), 'Seeing and Causes', Philosophy, 41: 348-355

Hinton, J.H. (1973), Experiences: an enquiry into some ambiguities. Oxford: Oxford University Press.

Houts, R. (1980), 'Some implications of the time-lag argument.' Philosophical and Phenomenological Research, 41: 150-157 
Humphrey, N. (2008), Seeing Red: A Study in Consciousness. Cambridge, MA., Harvard University Press.

Jacquette, D. (2004), 'Brentano's Concept of Intentionality', in D. Jacquette (ed.) The Cambridge

Guide to Brentano. Cambridge: Cambridge University Press.

Le Morvan, P. (2004), 'Arguments against direct realism and how to counter them.' American Philosophical Quarterly, 41: 221-234.

Le Poidevin, R. (2003), Travels in Four Dimensions. London: Oxford.

Le Poidevin, R. (2004), 'A Puzzle Concerning Time Perception', Synthese, 142: 109-142.

Lee, G. 2007. 'Consciousness in a space-time world', Philosophical Perspectives, 21: 341-374.

Lockwood, M. (1984a), 'Einstein and Identity Theory', Analysis, 44: 22-25.

--- (1984b), 'Reply to Gordon.' Analysis, 44: 127-128

Moore, G.E. (1953), Some Main Problems of Philosophy. London: Allen and Unwin.

Moritz, P.A. (1970), Man, Universe and Mind. Taunton: Martigan Publications.

Pace, M. (2007), 'Blurred Vision and the Transparency of Experience', Pacific Philosophical Quarterly, 88: 328-354.

Power, S.E. (2010), 'Complex Experience, Relativity and Abandoning Simultaneity', Journal of Consciousness Studies, 17: 231-256.

Price, H.H. (1950), Perception. Westport: Greenwood Press.

Prior, A.N. (1998), 'Some free thinking about time', in Van Inwagen, P. \& Zimmerman, D. (eds.)

Metaphysics: The Big Questions. London: Routledge.

Römer, O. (1929), 'The Finite Velocity of Light', in Shapley, H. \& Howarth, E. (eds.) A Source Book of Astronomy. London: McGraw-Hill.

Russell, B. (1948), Human Knowledge: its scope and limits. London: Allen \& Unwin.

Sider, T. (2003), Four-dimensionalism: An Ontology of Persistence and Time. London: Oxford University Press.

Smart, J.J.C. (1970), 'Sensations and brain processes?', in Baier, K. (ed.) The Mind-body 
problem. London: MacMillan.

Smythies, J. (2003), 'Space, Time and Consciousness', Journal of Consciousness Studies, 10: $47-56$

Tully, R.E. (1978), 'Sense-data and Common Knowledge', Ratio, 20: 123-141.

Tye, M. (2007), 'Qualia', in E. Zalta (ed.), The Stanford Encyclopedia of Philosophy (Fall 2007

Edition), Accessed 10 September, 2009. URL =

<http://plato.stanford.edu/archives/fall2007/entries/qualia/>.

Weintraub, R. (1998), 'The Spatiality of the Mental and the Mind-Body Problem', Synthese, 117: 409-417.

Zajonc, A. (1993), Catching the Light. Oxford: Oxford University Press.

Sean Enda Power

Department of Philosophy

School of Social Science and Philosophy

University College, Cork,

Ireland.

Email: seanendapower@gmail.com 
i Cases of seeing, hearing, tasting, and so on, are referred to here as cases of perceiving; one might also call them cases of sensing or sensory perception. In addition, by 'direct' perception I follow Austin's view: it is 'direct' in contrast to indirect perception; like Austin, I think of 'direct' as a 'trouser' word like 'real': it is applied to contrast it to cases which are not simply perception (Austin 1964). Here, it is in contrast to our sensing of something via something else, i.e., indirect perception.

Also, it may be that perceiving is more than just sensory experience, e.g., for perception, perhaps one needs to know what it is that they are experiencing; or, at least, have a concept of what they experience; or, perhaps, what appears to them must be what it seems to be in order that they perceive it. However, I will not debate these conditions for perception. This paper concerns what we can perceive (directly or indirectly); I put aside what is further needed for perception.

ii Loose reference is made here to to objects, events, entities, etc. as 'things', as in - 'what is that thing?'; 'How are things going with you?'; also, to the existence of things; in doing so, the existence of objects from the occurrence of events are not strictly distinguished. This is just for ease of expression; however important it may otherwise be, it does not seem to significantly alter this discussion.

iii This in/direct distinction may not only be true of our perception of external things; perhaps we indirectly perceive internal things as well, e.g., hunger. However, as will be discussed, perceptions of external things are particularly sensitive to the time-lag argument, so these are particularly focussed on in this paper.

iv Other philosophers have rejected reference to perceiving an intermediate entity, and insisted instead that we have modified perceptions or sense-acts. Adverbialists translate sentences which suggest we perceive something into sentences which eliminate the reference to a perceived thing, e.g., 'I see a red sense-datum' becomes 'I see redly'.

Adverbialism seems to be an attempt to avoid commitment to sense-data, which have the relevant properties that we seem to perceive. For example, if we must deny that physical objects are coloured, but they still seem to be coloured, adverbialists avoid sense-data that are coloured by insisting that, e.g., 'I perceive a red ball', is really 'I red-ly perceive a ball'.

The issue here is whether or not what we directly perceive can be external as it seems to be. It is assumed here that we directly perceive something. Perhaps we do not, even if we can directly perceive external things; however, space prevents considering this separate issue (e.g., Clarke 1987, Casullo 1987; for something similar, see Humphrey 2008). V This use of 'sense-data' is the common but not necessarily only use for this term. Moore introduces it in preference to an ambiguous use of 'sensation'; it seems that he originally meant the terminology to refer to whatever we directly see, hear, etc., and not necessarily to some internal entities which mediate our perceptions of external things. Given that understanding, there would be sense-data even given direct realism: external things would be sense-data. (For more on this usage, see, e.g., Moore 1953 and Tully 1978). However, the more common meaning is used here.

vi See later for a discussion on the time when the subject has the perception.

vii One option might be that we project these entities across external space in the moment we perceive them, e,g., after 
being stimulated by external events, we somehow beam what we directly perceive across external space to the places where the original events occurred. The intermediary entities will have to travel through this space instantaneously. Otherwise, the entities will not happen at distant places all at the same time.

viii Perhaps this would not hold for disembodied thinking beings. Can one seem spatially located if one only has thoughts? Could the world seem to have distant and external things to a disembodied spirit? What sense of 'here' could their thinking have?

ix However, that there is such a single place and time is just a convenience. As discussed further on, relativity raises complications with assuming any single moment for such activity. There is also a more general issue with assuming a single spatial location for such varied activity, even if it is internal. Such issues are discussed in more depth elsewhere, e.g., Power, ibid, and so neglected here. However, the special case of directly perceiving external things is key to this discussion.

$\mathrm{X}$ This issue is still an issue even if, as briefly stated, we insist mental entities have no spatial location. There is still the question of how one physical entity can correlate with a multiple of different mental entities.

xi An anonymous referee has suggested several objections to the application of relativity in this issue. Space precludes giving detailed responses to these here; some responses are already available in the literature (given at the end of this note).

(a) 'There may be little sense in applying 'frame of reference' relativities here. 'Suppose my experience is of seeming to hear a certain note at the same time as seeming to see a certain colour patch. What does it mean to say that, within another frame of reference I am hearing one noticeably after the other?'

This is discussed in Power (ibid). Briefly, it is this: it is agreed that whether or not one seems to hear a note at the same time as seeing a colour patch does not vary according to a frame; if you occupy a different frame to me, what you perceive will not be different for me because of that (it is not even clear what that could mean).

However, as argued in Power, because of this, given relative time, (a) the different elements of what we perceive are not simultaneous and (b) apparent simultaneity to merely apparent simultaneity (perhaps only a failure to perceive duration). As such, we merely seem to hear the note at the same time as seeing the colour patch, but we do not really do so. An analogy may help: The simultaneity of what we directly perceive is analogous to the smoothness of what we feel when touching a polished table.

(b) 'A more irenic response would be to suggest that the reference frame relativity available to two events as close as those taking place in the same brain would be such that it would always fall below the threshold of what time differences we can discriminate - so they would be phenomenologically simultaneous in all frames.'

Two events in the brain may be so close in occurrence that someone observing them as brain events will observe them as seeming to be simultaneous. In addition, as argued in Power (ibid), these events may appear to the subject of the brain events to be simultaneous. Yet, that does not make them actually simultaneous; it just makes them seem so because, e.g., in the case of other observers, they are separated by so brief a duration (the subject's own case is more complicated; see Power, ibid). That is, they merely seem to be simultaneous. 
Consider this 'merely seem'; if 'phenomenological simultaneity' refers merely seems to be simultaneity, then it is not actual simultaneity; but if phenomenological simultaneity means something stronger, that is, apparent simultaneity which is actual simultaneity, then it is simultaneity. Thus, we either have relative simultaneity or, again, non-physical simultaneity (see above). 